\title{
Use of Light Detection and Ranging (LiDAR) to Obtain High- Resolution Elevation Data for Sussex County, Delaware
}

\section{Need for High-Resolution Elevation Data}

Sussex County, Delaware, occupies a 938-square-mile area of low relief near sea level in the Atlantic Coastal Plain (fig. 1). The county is bounded on the east by the Delaware Bay and the Atlantic Ocean, including a barrier-island system, and inland bays that provide habitat for valuable living resources. Eastern Sussex County is an area of rapid population growth with a long-established beachresort community, where land elevation is a key factor in determining areas that are appropriate for development. Of concern to State and local planners are evacuation routes inland to escape flooding from severe coastal storms, as most major transportation routes traverse areas of low elevation that are subject to inundation. The western half of the county is typically rural in character, and land use is largely agricultural with some scattered forest land cover. Western Sussex County has several low-relief river flood-prone areas, where accurate high-resolution elevation data are needed for Federal Emergency Management Agency (FEMA) Digital Flood Insurance Rate Map (DFIRM) studies.

In 2004, available U.S. Geological Survey (USGS) and State of Delaware elevation data for Sussex County consisted of topographic maps depicting 5-foot and 10-foot contours shown in graphic form and 30-meter digital elevation models (DEMs). These data were inadequate in resolution and detail for DFIRM studies and local planning needs. The USGS elevation data for this area were not standardized or integrated with any other elevation data sets and were too coarse to be integrated with other large-scale, high-resolution framework geospatial data used by government agencies or the private sector in new regulatory and scientific studies. The most immediate need for high-resolution elevation data was in the updating of FEMA DFIRMs by the Delaware Department of Natural Resources and

Environmental Control (DNREC). Other needs for high-resolution elevation data included National Oceanic and Atmospheric Administration (NOAA) and USGS sea-level-rise projections;

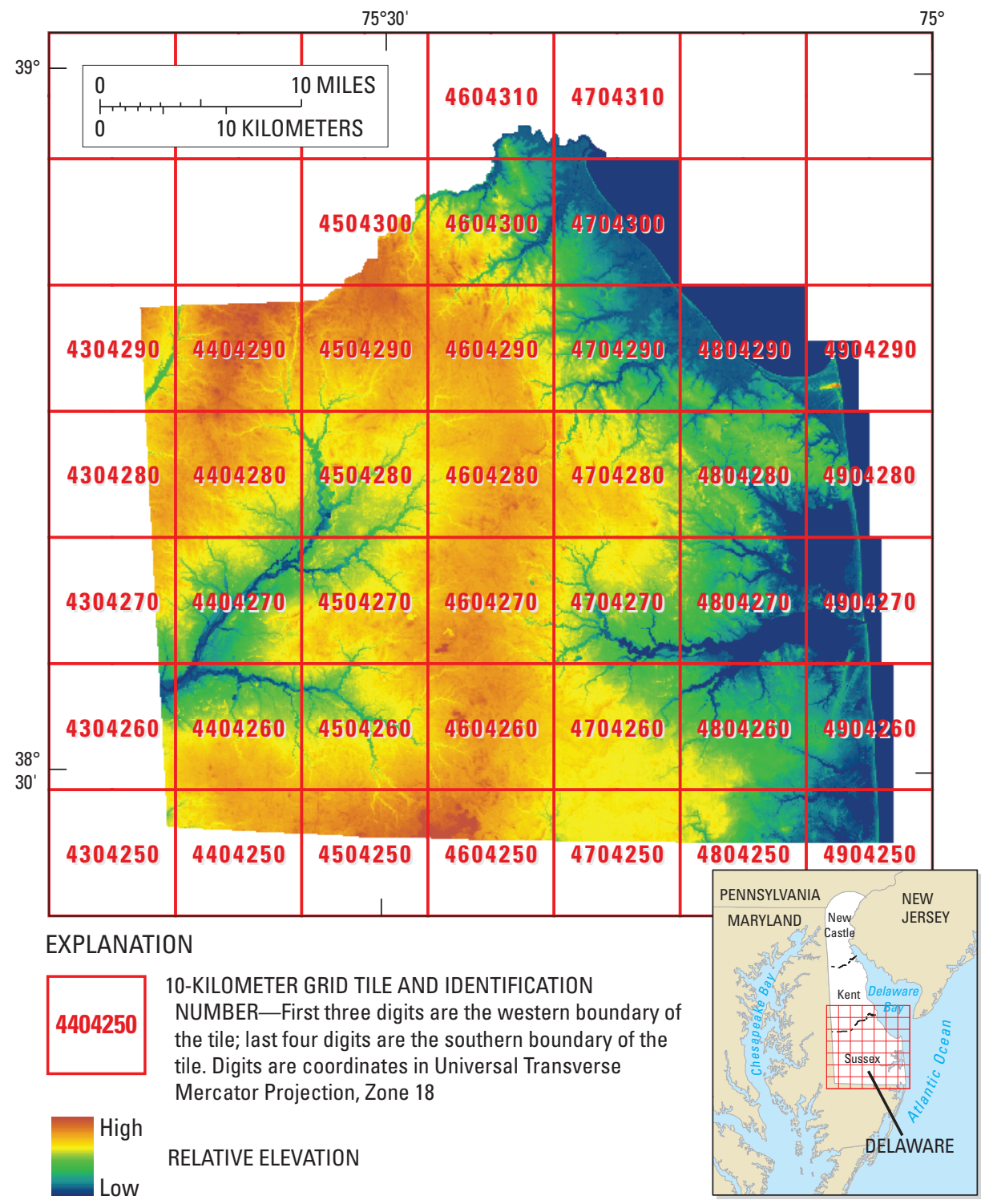

Figure 1. LiDAR collection area showing 10-kilometer by 10-kilometer tiles for which digital elevation model and 2-foot topographic contours were produced. Parsing data into tiles enhances data display and facilitates data analysis by minimizing computer hardware and software response time. 
storm-surge-prediction mapping by the U.S. Army Corps of Engineers; predicting habitat change and updating maps of ditches and ditch flow regimes by DNREC; soil-resource studies by the U.S. Department of Agriculture Natural Resources Conservation Service (NRCS); and revision of geologic base maps by the Delaware Geological Survey (DGS).

\section{What is LiDAR?}

Light Detection And Ranging (LiDAR) is an optical remote-sensing technology that is used to determine the distance of a target from the sensor by measuring some of the basic properties of a reflected laser light pulse, such as intensity and timing. The principle of airborne LiDAR is that laser pulses aimed toward the ground are emitted from an aircraft at known times. When light strikes a feature (referred to as a target) on the ground, some of it is scattered while the remaining light energy is reflected back to an aircraft-mounted receiver. Target coordinates $\mathrm{x}, \mathrm{y}$, and $\mathrm{z}$ are calculated using on-board and base-station Global Positioning System- (GPS) derived aircraft location, the speed-of-light constant, and laser-pulse geometry (distance and angle of the pulse). Rapid laser pulsing increases the light's ability to penetrate vegetation and reach the Earth's surface. The collected set of target points for an area is known as "mass points." From selected mass points, derivative products such as topographic contours and DEM data are produced. The maximum vertical resolution of most commercial LiDAR instruments in 2004-05 was about $15 \mathrm{~cm}$ (centimeters) when standard groundcontrol procedures were used to ensure accurate data-point location.

LiDAR is especially useful in lowelevation and low-relief areas because of its ability to detect small changes in land elevation. It can also be used to collect elevation data over large areas in remote locations more affordably than equivalent ground surveys, to provide elevation data for modeling of inundation due to precipitation runoff or coastal storm flooding, and to provide data that can be readily combined with other data in geographic information systems (GIS) for analysis. LiDAR data can be integrated easily with the high-resolution orthoimagery acquired by the State of Delaware in 2002 and 2007.
Elevation is one of the primary data themes of The National Map (http://nationalmap.gov/). The National Elevation Dataset (http://ned.usgs.gov/) provides access to DEM data. Contours are a Delaware spatial data framework layer to be provided from the Delaware DataMIL (http://datamil.delaware.gov/), an Internet mapping server that provides the most current base map of Delaware. The USGS, DGS, and NRCS were interested in bringing accurate, highresolution data into the public domain for use in planning and decisionmaking at all governmental levels by providing access to 2-foot contour data to update the elevation framework layer for use in Delaware DataMIL-generated topographic maps and future USGS topographic map products. With these requirements known, the USGS, in cooperation with the DGS and NRCS, initiated a project designed to produce bare-earth mass points; a tiled, bare-earth, 2-meter DEM; 2-foot topographic contours, edited and filtered; and Federal Geographic Data Committeecompliant (Federal Geographic Data Committee, 2006) project metadata for Sussex County.

This fact sheet describes the methods and techniques used to collect and process LiDAR elevation data, the generation of the DEM and the 2-foot contours, and the quality-assurance procedures and results. It indicates where to view metadata on the data sets and where to acquire bare-earth mass points, DEM data, and contour data.

\section{Data Collection and Processing}

Several options for collecting statewide high-resolution elevation data were examined. LiDAR was selected because of the following capabilities: ability to collect high-resolution data in a relatively large area in a short time, using aircraft; cost effectiveness when compared to detailed topographic field surveys of the same vertical resolution and areal extent; ease of data collection in remote and inaccessible areas; ability to collect and process data for more than one elevation product (bare-earth, tree canopy) from one data set; and ability to integrate with other data layers, such as orthoimagery.

The selection of the National Aeronautics and Space Administration (NASA) Experimental Advanced
Airborne Research LiDAR (EAARL) to collect high-resolution elevation data for Sussex County was based on several key factors (U.S. Geological Survey, 2007a):

- Geographic proximity (the NASA EAARL aircraft was based 10 miles south of Sussex County, Delaware).

- Operating altitude of 300 meters above ground level (lower than normal commercial LiDAR collection operation).

- Dual green laser wavelengths (532 and 1,064 nanometers), which have the ability to penetrate non-turbid water to produce subsurface contours.

- Simultaneous multi-channel waveform digitizer.

- Real-time LiDAR waveform processing, allowing potential data users to process data in multiple ways to examine different levels of vegetation and produce a bare-earth DEM.

- Proven capability for vertical resolution of features exceeding FEMA's 18.5-cm standard.

NASA EAARL data for Sussex County were collected during leaf-off foliage condition from late February 2005 to early April 2005. Elevation data were collected with sufficient point density to create accurate data values for a grid of points arrayed in squares 2 meters by 2 meters, a DEM that represents a sampling of the mass points collected at the surface of the Earth. Data were denser in areas of flight-line overlap and also where collected in cross flight paths during each collection flight for data-verification and quality-assurance purposes. A GPS base station, a station that is stationary at or near ground level over a monumented position while continuously receiving data from satellites the instrument is tracking, was established in the scheduled LiDAR acquisition area. Locational data referenced among three or more GPS satellites, the base station, and the aircraft were collected at 1-Hertz intervals at least 1 hour prior to data-collection flights, during flights, and for at least 30 minutes after flights to correct aircraft location with respect to the ground.

The software used to process the collected EAARL LiDAR data is the 
Airborne LiDAR Processing Software (ALPS), developed collaboratively by the USGS and NASA. The ALPS software was installed in new Linux hardware and tested with a sample data set, then verified with NASA oversight before the processing of the Sussex County data began.

ALPS characteristics include (U.S. Geological Survey, 2007b):

- Open source code and freely available processing algorithms (such as bareearth routines and filters).

- Cost-free distribution.

- Ability to operate in a Linux environment.

- Data-viewing software that processes raw EAARL data into various products.

- Collegial development environment in which users are encouraged to submit enhancements to existing code for NASA review and acceptance.

The LiDAR data can be processed in different ways, resulting in various products. When initially processed from the on-board aircraft computing system, LiDAR data consist of many thousands of irregularly spaced points, each with horizontal coordinates and an elevation value. In this project the mass points were processed to yield a bare-earth data set. All mass points determined to be from manmade features on or near the land surface were removed. The removal of mass points to create the bare-earth data set is to a large extent an automated process, and the ALPS software was used to delete an estimated 97 percent of data returns from buildings and other features. Almost all data points determined to be from vegetation were also removed using the ALPS software. The 3 percent of mass points not removed by ALPS were anomalies, such as birds or aircraft in flight, high-voltage electrical wires, the tops of telephone poles, and especially buildings that were not recognized by ALPS. These remaining mass points were removed by manual inspection and comparison of mass points to feature identification using orthoimagery. ArcMap software was used to create shape-files of the bare-earth mass points data set (see figure 2), which in turn were used to produce a DEM.

\section{Digital Elevation Model Generation}

DEMs are simple data sets that are easy to store and manipulate. A DEM form set of interpolated bare-earth mass points in a gridded array. Because a DEM surface is interpolated, it is slightly less accurate than the mass points (Bales and others, 2007) or a Triangulated Irregular Network (TIN). Because LiDAR data points are randomly placed and the DEM is a gridded version of these points, the surface is typically displayed as a uni-
DEM surface may omit small details associated with larger features, such as roadside ditches or the location of a streambank lip. Break-line information can be added to a DEM to restore some omitted small features and details, but the resulting improvement is often considered small when compared with the time and cost required to integrate such data.

The shape-files of the bare-earth mass points were transferred to the appropriate 10-kilometer by 10-kilometer tiles with sufficient overlap data to ensure proper tile joining. A 2-meter

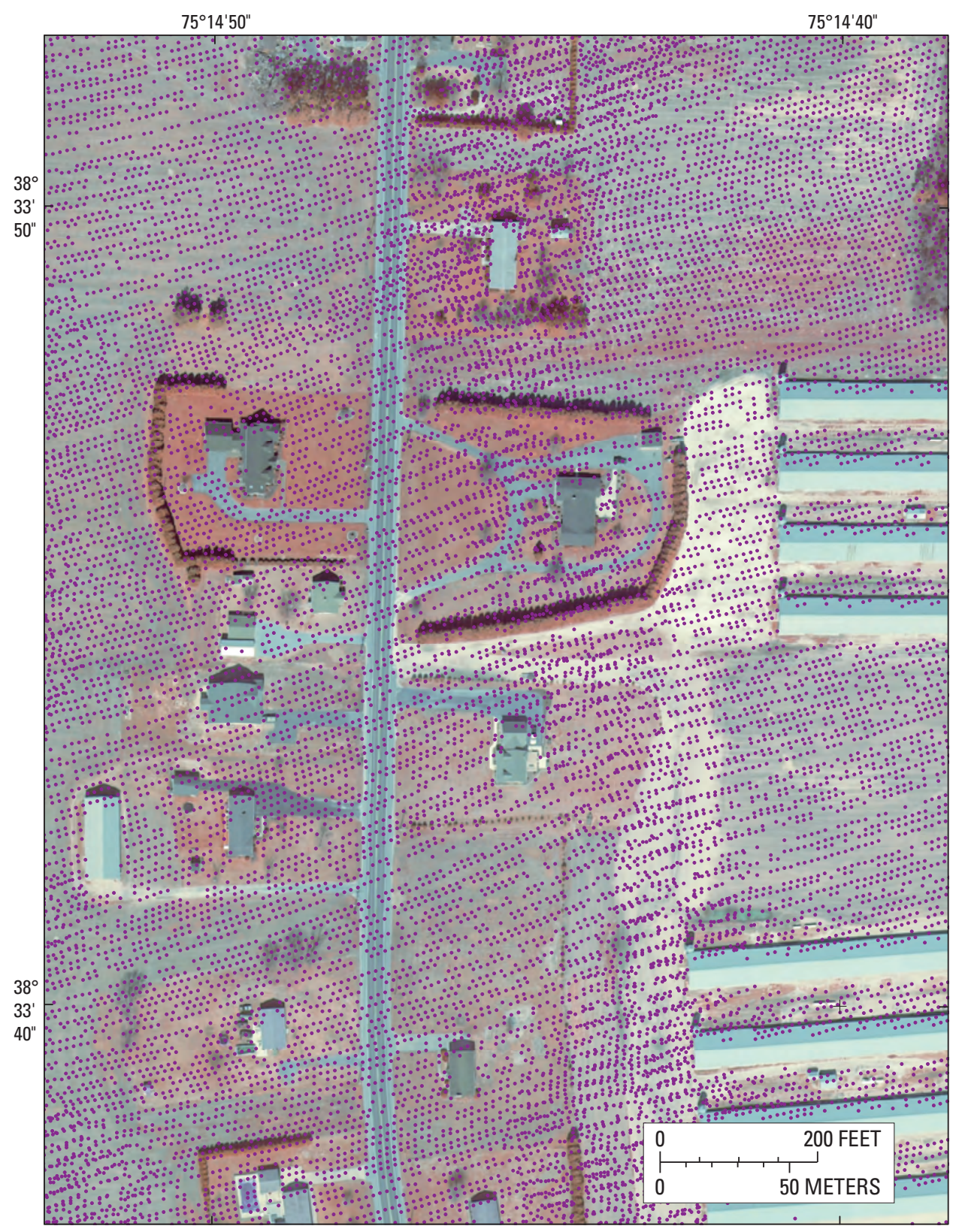

Figure 2. Bare-earth LiDAR mass points superimposed on corresponding 1-foot-resolution orthoimage of Sussex County, Delaware. This image illustrates the density and distribution of bare-earth LiDAR mass points. Mass points have been removed for buildings and some vegetation where the LiDAR did not reach ground level. 
noise-reduction filter was applied to the data points to reduce the irregularity of the model surface while preserving data accuracy and subtle terrain features. The data set required 40 tiles to cover the 938-square-mile area of Sussex County. Quick Terrain Modeler, a software application tool for visualization and feature extraction from large digital elevation surface data sets, was applied to the variably spaced noise-filtered points to create an interpolated 2-meter DEM for each tile.

A second filtering process was applied to the DEM surface data. It was weighted specifically to reduce small, sharper irregularities in the DEM surface, especially in lower relief, low-elevation areas. This second filtering process produced a relatively smooth elevationmodel surface by removing small highrelief spikes and pits, which tend to be uncharacteristic in low-lying, low-relief areas, while having a minimal effect on data accuracy. This second filtering process also applied little smoothing in higher elevation, greater relief terrain. The DEM was then hydrographically enforced, so that streams and lakes are connected where the DEM data are not distinct and so that water will flow downslope when modeled to do so. To accomplish the hydrographic enforcement, hydrography vector data from the National Hydrographic Dataset (NHD) (http://nhd.usgs.gov/) was overlaid on the DEM and used as a guide to manually connect lakes and streams on the DEM. Next, the open-water surface areas within water-feature polygons were flattened to a uniform height to eliminate waves sensed by the LiDAR. The flattened open water enhances the visual recognition and differentiation of the lakes, bays, and streams from land areas. The DEM was then given a final inspection and edited to eliminate remnants of manmade structures or any remaining vegetation responses from the LiDAR. The DEM data were then converted to Arc ASCII Grid file format. The example of DEM data overlaid with orthoimagery shown in figure 3 is indicative of the detail that each provides. When georegistered to each other, orthoimagery and DEM data create a powerful information data set that can be used to visualize events and support decisionmaking.

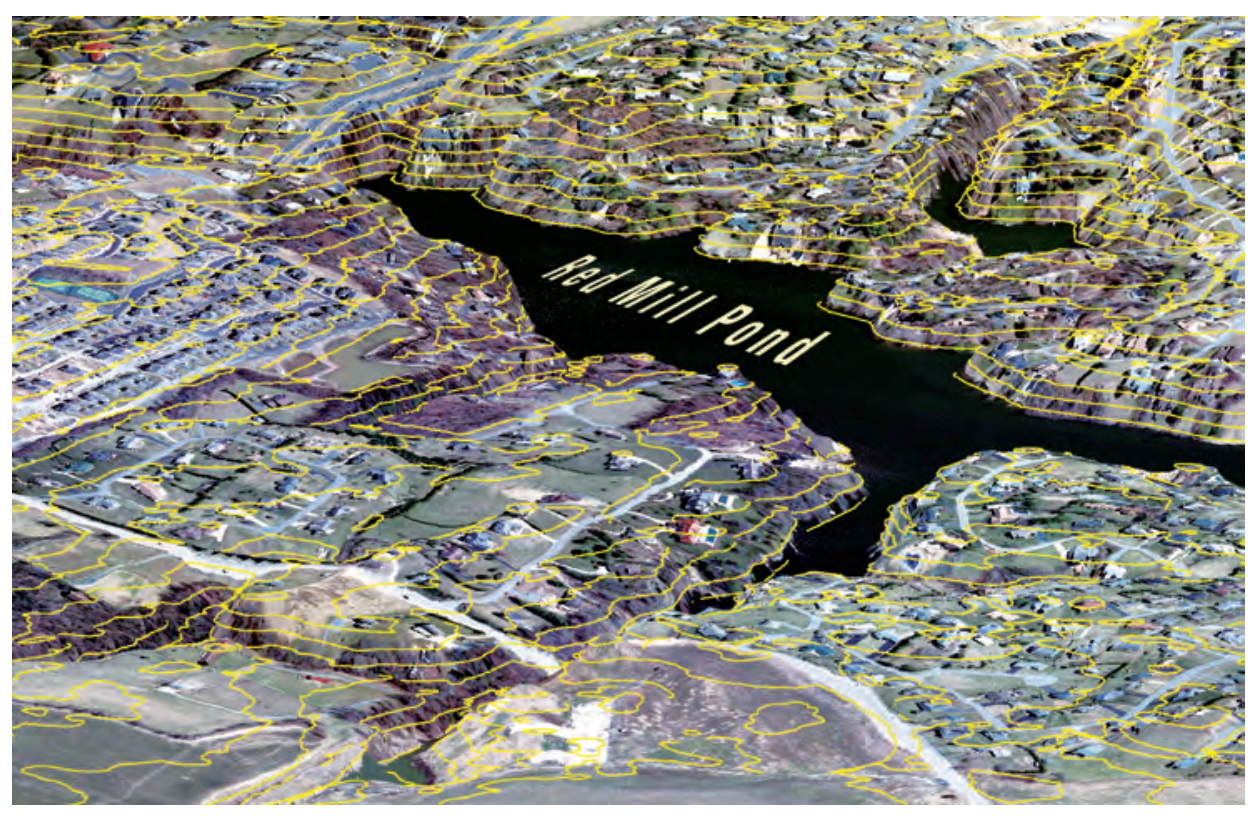

Figure 3. LiDAR digital elevation model of Sussex County, Delaware, integrated with 2007 1-foot color-infrared orthoimagery (rectified digital aerial photography) draped over it. Twofoot contours (yellow lines) have been overlaid on the orthoimagery. This figure illustrates that different imaging techniques and linear data can complement each other.

\section{Generating Topographic Contours}

Global Mapper software was used to generate contour data from the DEM data. A low simplification factor was used in Global Mapper to increase the number of vertices per unit length of contour, resulting in a smoother contour than would be generated if no vertices were added to the DEM data. The contour data were then filtered to remove numerous small, closed contour tops and depressions within a contour interval that had a linear on-the-ground length of less than 80 feet. Any contour with only two vertices that was less than 20 feet in length also was deleted. Elevation values, in feet, are embedded with each contour line. The contour files were then converted to shape-files. Contour lines that that continue between adjacent tiles (depicted in figure 1) share a common vertex on the tile boundary, so that contours appear continuous when tiles are joined together.

For additional detail and description of the process and software used in producing DEM data and contours for this project, refer to the contour metadata files posted on the Delaware DataMIL (http://datamil.delaware.gov/) and the DEM metadata posted on the National Elevation Database web site (http://ned. usgs.gov/). An example of the final result of the contour generation specifications and process is shown in figure 4 .

\section{Quality Assurance}

\section{Guidance}

The American Society of Photogrammetry and Remote Sensing (ASPRS) Guidelines For Vertical Accuracy Reporting For LiDAR Data, version 1.0 (American Society of Photogrammetry and Remote Sensing, 2004), were used for reference on vertical-accuracy evaluation. Vertical accuracy is the principal criterion used to evaluate the quality of the elevation data produced, and therefore the degree of confidence the data user can have in the data. Vertical-accuracy requirements depend on the intended user applications. There are four primary applications of digital-elevation data sets for which high vertical accuracy is typically required:

- Infrastructure management of dense urban areas where planimetric maps are typically required at scales of 1 inch:100 feet or larger.

- Stormwater and floodplain management in flat terrain.

- Management of wetlands and other ecologically sensitive low-lying areas.

- Marine navigation and safety. 
Many applications not listed above do not require the highest accuracy achievable. Users of elevation data need to balance the requirement for accuracy with the increased cost of obtaining higher accuracy elevation data; other processing options, such as hydrographic enforcement (which ensures that streams are connected and flow downslope); or product choices, such as topographic contours. The capability of the NASA-EAARL data to produce data that exceeded the FEMA Appendix A (Federal Emergency Management Agency, 2003) specification to resolve $18.5-\mathrm{cm}$ vertical features was a primary benefit for DNREC, which is responsible for DFIRM mapping in Sussex County, which has many inhabited low-lying, low-relief areas. The National Standard for Spatial Data Accuracy (National Spatial Data Infrastructure, 1998) was used as guidance to report vertical accuracy of the NASA-EAARL processed bare-earth mass points for this project. ASPRS Guidelines for Vertical Accuracy Reporting for LiDAR Data state that a minimum of 20 checkpoints for each major landcover type identified in the acquisition area shall be tested and must provide a 95-percent confidence level to meet the standard. The checkpoints shall be distributed to reflect areas of geographic interest and the distribution of error in the data set. When 20 points are tested for each land-cover type, the 95-percent confidence level allows 1 point to fail in order to meet product specifications. It is not acceptable practice to collect an abundance of checkpoints and retain only points that meet or exceed vertical-accuracy reporting criteria. These guidelines were followed for two land-cover categories in Sussex County as a quality-assurance test of the LiDAR mass points.

\section{Procedures}

To test the accuracy of selected bareearth LiDAR points, 913 GPS-surveyed ground-control points in Sussex County were obtained from NRCS. These 913 control points were divided between two major land-cover categories: agricultural fields, and farm lanes and roads. A total of 913 LiDAR bare-earth points closely corresponding to the GPS-surveyed ground-control points were selected using GIS methods to compare vertical height readings. Of the 913 NRCS control points, 144 were located along farm lanes and roads and 769 were located in agricultural fields. The locations of the GPS-surveyed points and the selected bare-earth LiDAR mass points were required to be within 1 meter surface distance from each other for point-topoint comparison. The graph shown in figure 5 is a quantitative comparison of elevation between points surveyed by traditional GPS methods and the Sussex County LiDAR data set for the two land-cover classes specified.
In figure 5, red symbols represent the farm lanes and roads land-cover category and black symbols represent the agricultural fields land-cover category. The regression line indicates a strong relation $\left(R^{2}=0.7757\right)$ between the LiDAR mass points and the corresponding GPS control points.

\section{Results}

Results of the quality-assurance analysis indicate an aggregate average vertical accuracy for both land-cover

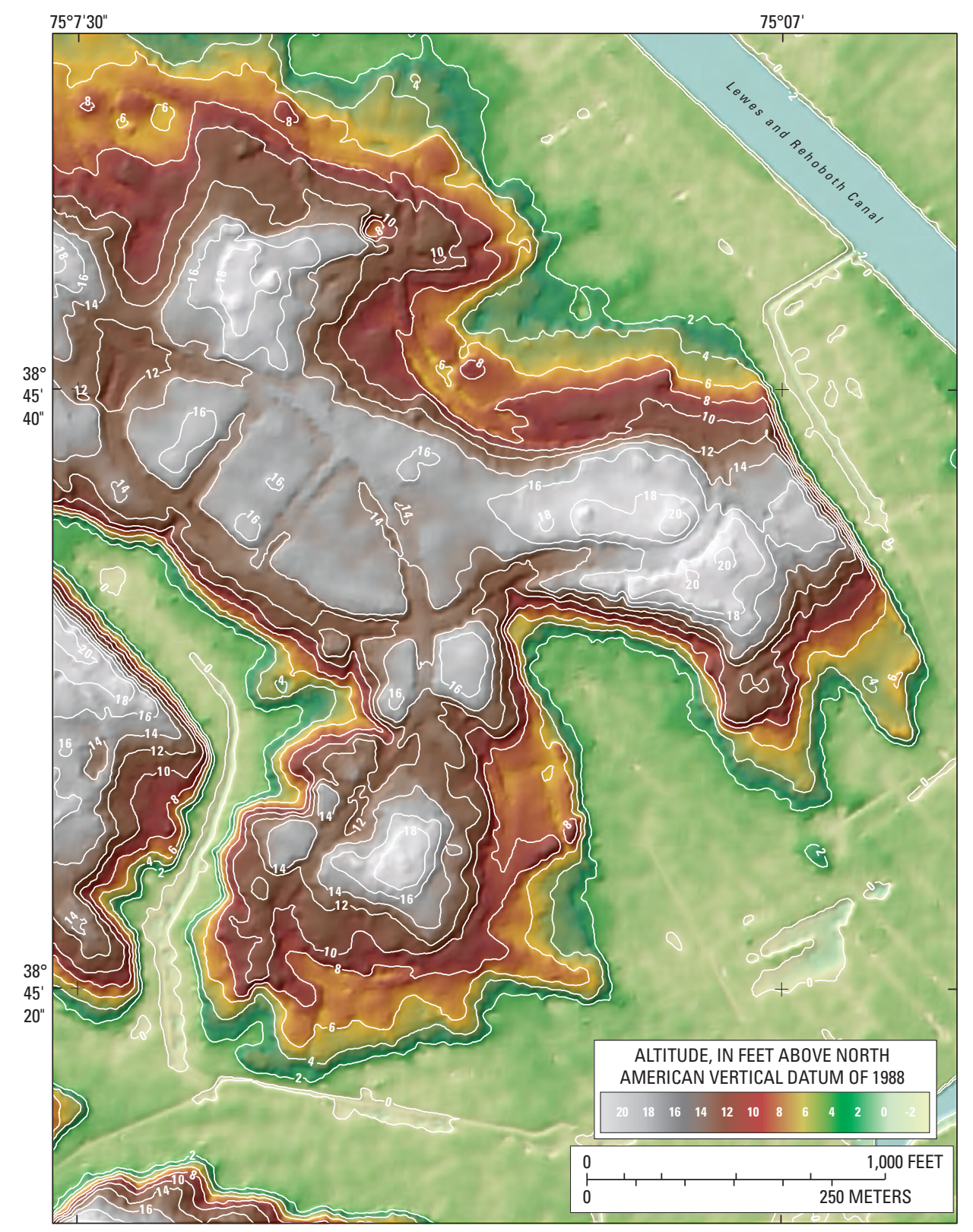

Figure 4. Two-foot topographic contours derived from 2-meter gridded elevation model of the area near Wolfe Neck, Delaware. Color has been added to water areas (blue) and to the land area (grading from green (low elevation) to gray (highest elevation shown)). These bare-earth (buildings and vegetation removed) elevation data depict part of a subdivision, wetland areas, and the Lewes and Rehoboth Canal. 
classes tested of $14.8 \mathrm{cms}$, which is more accurate than the established $18.5-\mathrm{cm}$ FEMA standard. The root mean square error (RMSE) value for each individual land-cover class also surpassed the RMSE established by FEMA. The 2-meter gridded DEM meets or exceeds \pm 18.5 -cm vertical-accuracy standard for FEMA DFIRM products. The contours generated from the DEM were compiled to meet a standard of $15 \mathrm{cms}$ vertical accuracy at a 95-percent confidence level.

\section{Disclaimer}

Any use of trade, product, or firm names in this report is for descriptive purposes only and does not imply endorsement by the U.S. Government.

-by Roger A. Barlow, Mark R. Nardi, and Betzaida Reyes

\section{References Cited}

American Society of Photogrammetry and Remote Sensing, 2004, ASPRS guidelines, Vertical accuracy reporting for LiDAR data, Version 1.0, May 24, 2004, accessed January 17, 2008, at http://www. asprs.org/society/committees/lidar/downloads/Vertical_Accuracy_ Reporting_for_Lidar_Data.pdf

Bales, J.D., Wagner, C.R., Tighe, K.C., and Terziotti, S.E., 2007, LiDAR-derived flood-inundation maps for real-time flood-mapping applications, Tar River Basin, North Carolina: U.S. Geological Survey Scientific Investigations Report 2007-5032, 42 p.

Federal Emergency Management Agency, 2003, Guidelines and specifications for flood hazard mapping partners-Appendix A: Guidance for aerial mapping and surveying, p. A10-A14, A39-A47, and A49-A53, accessed January 18, 2008, at http://www.fema.gov/ library/viewRecord.do? $i d=2206$

Federal Geographic Data Committee, 2006, Geospatial metadata: Accessed June 18, 2008, at http://www.fgdc.gov/metadata/

National Spatial Data Infrastructure, Federal Geographic Data Committee, Subcommittee for Base Cartographic Data, 1998, Geospatial positioning accuracy standards, Part 3: National standards for spatial data accuracy, FGDC-STD-007.3-1998, p. 3-1-3-25, accessed June 18, 2008, at http://www.fgdc.gov/standards/projects/FGDC-standardsprojects/accuracy/part3/chapter3

U.S. Geological Survey, 2007a, Center for Coastal and Watershed Studies, Integrated Remote Sensing and Modeling Group, Advanced methods, EAARL - Airborne LiDAR system for high-resolution submerged and sub-aerial topography, accessed January 19, 2008, at http://coastal.er.usgs.gov/remote-sensing/advancedmethods/eaarl.html

U.S. Geological Survey, 2007b, Center for Coastal and Watershed Studies, Integrated Remote Sensing and Modeling Group, Advanced methods, LiDAR processing systems, accessed January 19, 2008, at http://coastal.er.usgs.gov/remote-sensing/advancedmethods/lidar.html

\section{Data Availability}

- The Sussex County DEM data will be made available on the USGS National Elevation Dataset (NED) web site for downloading at http://seamless.usgs.gov/website/seamless/ products/9arc.asp. The DEM data will be offered in four data formats: ArcGrid, bil, TIFF, and GridFloat.

- The contours will be available for downloading from the Delaware DataMIL web site at http://datamil.delaware.gov/.

- Metadata for the DEM and contour data will be available from the Delaware DataMIL web site and the Geospatial One-Stop web site at http://gos2.geodata.gov/wps/portal/gos/.

- Mass points will be distributed from the USGS Center for LiDAR Information Coordination and Knowledge (CLICK) at http://gisdata. usgs.net/website/lidar/.

\section{For more information, contact:}

Roger A. Barlow

National Spatial Data Infrastructure Partnership,

Eastern Region Liaison

U.S. Geological Survey

563 National Center

Reston, VA 20192

E-mail: rbarlow@usgs.gov

Web: http://www.usgs.gov/ngpo/ 